\title{
STABILITY ENHANCEMENT OF A POWER SYSTEM WITH WIND GENERATION USING ANN BASED STATCOM
}

\author{
E.R. Mauboy, T. T. Lie
}

Dept. of Electrical and Electronic Engineering Auckland University of Technology

New Zealand

Email:emauboy@aut.ac.nz;tek.lie@aut.ac.nz

\begin{abstract}
This paper examines the impact of a high penetration of Squirrel Cage Induction Generator wind turbines (SCIGs) on the voltage regulation and reactive power compensation on a grid. It shows that SCIGs slow down voltage restoration after a voltage drop and can lead to voltage and rotor speed instability. When the voltage is restored, SCIGs will absorb reactive power and, if the voltage does not return quickly enough, the generator accelerates and consumes larger amounts of reactive power. This situation is exacerbated if the wind turbine is connected to a weak power system.
\end{abstract}

A static synchronous compensator (STATCOM), can be utilised to maintain the voltage profile and to overcome a transient disturbance after faults. However, existing STATCOMs utilise fixed gain PI controllers that are unable to respond when the system is under extreme conditions such as a three phase to ground fault, sudden wind speed changes, load fluctuations and weak grid support. Therefore, in this work, an artificial neural network (ANN) based self-tuning PI controller is proposed. Simulation studies were conducted to demonstrate the effectiveness of the proposed controller in maintaining the system stability under such conditions.

Keywords: Voltage Stability, Wind Power Generation, STATCOM, ANN

\section{INTRODUCTION}

Connecting generators supplied by non-dispatchable energy sources, such as wind, into the existing electricity grid system poses many problems, particularly maintain voltage and frequency stability. When the penetration of non-dispatchable energy is increased in the electricity grid, the way of controlling the frequency must be changed, as the grid frequency is controlled by conventional power plants $[1,2]$. To maintain voltage stability, electrical power system components that are capable of absorbing or injecting reactive power need to be controlled. Under transient conditions, such as after

\author{
T. N. Anderson
}

Dept. of Mechanical Engineering Auckland University of Technology New Zealand

Email: tanderso@ aut.ac.nz

faults, there is a need for automated controllers to help the system counter the voltage instability.

To prevent these types of instabilities, conventional shunt capacitor banks are typically connected to the generator terminal to compensate for its reactive power consumption. However this is not always sufficient in the case where wind turbines using SCIGs are connected to a weak grid. Also, when the variation of wind speed is high, as a function of the output power, it causes fluctuations in the system voltage. Dynamic compensation means including: static synchronous series compensators (SSSC), unified power flow controllers (UPFC), unified power quality controllers (UPQC), static VAR compensators (SVC) and STATCOM [3, 4] are therefore used in voltage regulation through the reactive power needed.

Various shunt Flexible AC Transmission Systems (FACTS) devices for supporting reactive power compensation are needed to overcome voltage instability after large disturbance system faults or load demand changes. STATCOM devices can enhance and maintain voltage profile after faults or transient disturbances [4, 5]. In addition they offer the ability to work for different functions at the same time, follow the rapid load changes, the size is smaller than the same controller devices and are easy to adapt the varying load conditions [4, 5]. However, existing STATCOM utilizes a fixed gain PI controller that operates under system normal nominal load conditions and without fault occurrences. However, the controller performance will degrade if the system operation changes due to load fluctuations, fault conditions and weak grid support. Therefore, there is a need for a controller where the $\mathrm{P}$ and I gain can be automatically adjusted to cope with these conditions.

\section{PROBLEM FORMULATION}

\section{A. Basic design of a STATCOM and its control system}

A STATCOM device regulates the voltage by controlling the reactive power into the system using its capacitive capability to generate reactive power 
for compensating the system voltage drop or absorbing reactive power in inductive mode when the voltage is swell [6].

The adjustment of the reactive power in this controller is done by a Voltage-Sourced Converter (VSC) connected to a coupling transformer, using forced-commutated power electronic devices such as Gate Turn off (GTO), Insulated-Gate Bipolar Transistor (IGBT) or Integrated Gate-Commutated Thyristor (IGCT) to synthesize the voltage $V_{2}$ from the direct current (DC) voltage source. Figure 1 illustrates the operating principle of the STATCOM with the active and reactive power transfer between the source $V_{1}$ and $V_{2}$ (see equation (1)). $V_{1}$ is the system voltage to be controlled and $V_{2}$ is the voltage generated by the VSC [7].

$$
P=\left(V_{1} V_{2}\right) \sin \delta / X, Q=V_{1}\left(V_{1}-V_{2} \cos \delta\right) / X
$$

Where $\mathrm{P}$ is the active power, $\mathrm{Q}$ is the reactive power; $V_{1}$ and $V_{2}$ represent the system voltage to be controlled and the voltage generated by the VSC respectively; $X$ is the reactance and $\delta$ is the phase angle between $V_{1}$ and $V_{2}$.

From the control loop of the STATCOM, there are three regulators that determine the desired value of voltage and current in order to control the reactive power flow to the grid.

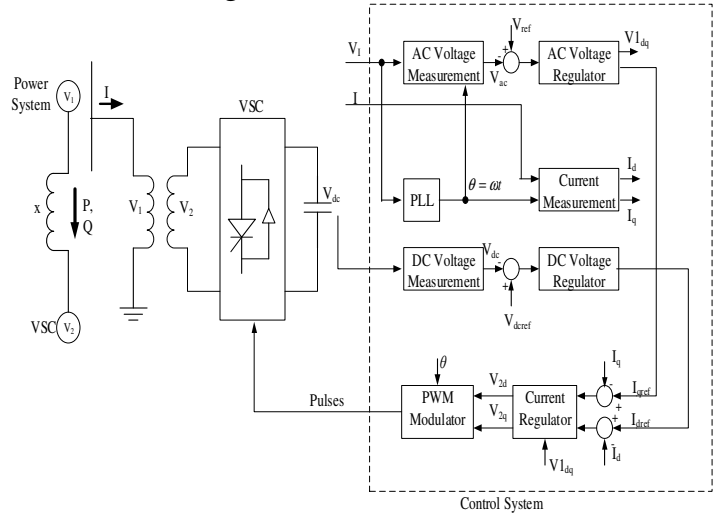

Figure 1. STATCOM Control Loop

Each of the regulators has the controller gains that needs to be determined as shown in equations (2) (6). The control loop of the STATCOM is shown in Figure 1 [7] and consists of an AC voltage regulator, a DC voltage regulator and a current regulator. The $\mathrm{AC}$ voltage regulator and the DC voltage regulator generate the reference current $I_{d r e f}$ and $I_{\text {qref }}$ as the input for the current regulator. $I_{d}$ that controls active power flow is the current in phase with the voltage, while $I_{q}$ controls reactive power flow is in quadrature with the voltage. The $V_{a c}$ regulator, as the main regulator, determines the reactive power needed from the $I_{q}$ value, which is regulated through the $\mathrm{P}$ and I gain to get a sufficient value to control the reactive power, whether it is generated or absorbed [7, 8]. The current regulator input is from the AC and DC voltage regulators, $I_{d q r e f}, I_{d q}$ and $V_{d q 1}$ for output $V_{d q 2}$ as an input to PWM modulator [7, 8]. AC Voltage Regulator

$$
I_{q} r e f=\left(V_{a c} r e f-V_{a c}\right) \times\left(K_{p-} V_{a c}+K_{i_{-}} V_{a c} \times \frac{1}{s}\right)
$$

DC Voltage Regulator

$$
\begin{gathered}
I_{d} r e f=\left(V_{d c} r e f-V_{d c}\right) \times\left(K_{p_{-}} V_{d c}+K_{i_{-}} V_{d c} \times \frac{1}{s}\right) \\
V_{d q}=\left(V_{d}+I_{q} \times K_{f}-V_{d}{ }^{\prime}\right) \times\left(V_{q}-I_{d} \times K_{f}-V_{q}{ }^{\prime}\right)
\end{gathered}
$$

Where

$$
\begin{aligned}
& V_{d}{ }^{\prime}=\left(I_{d} r e f-I_{d}\right)\left(K_{p}+K_{i} \times \frac{1}{s}\right) \\
& V_{q}{ }^{\prime}=\left(I_{q} r e f-I_{q}\right)\left(K_{p}+K_{i} \times \frac{1}{s}\right)
\end{aligned}
$$

In the STATCOM model (Figure 2 [7]), the P and I gains are fixed values found by trial and error. This simple structure is reliable when used under steady operating conditions. However, this method has a number of limitations. It is not robust enough especially under external disturbance, structural perturbations during operation and changes in parameters such as different loading levels and fault types

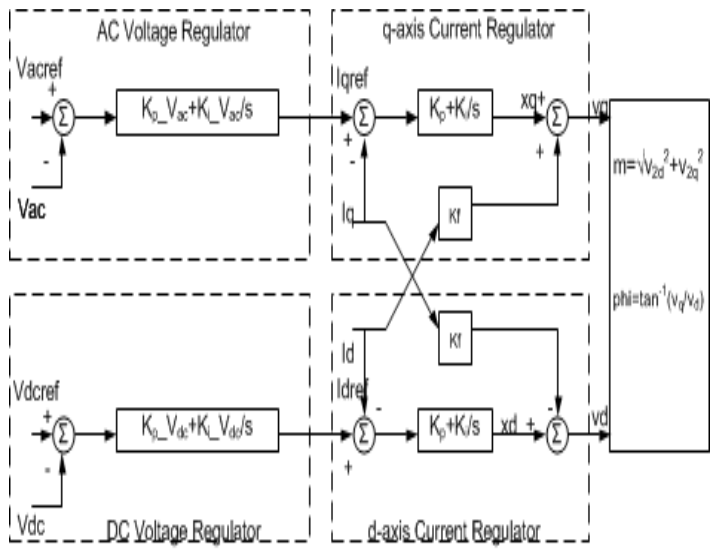

Figure 2. Fixed-gain PI Controller for STATCOM

To overcome this, it is necessary to develop the controller such that it can perform under a wider range of operating conditions and act based on real time situations.

\section{B. Artificial Neural Network}

One means of achieving this, is by utilising an ANN self-tuning PI controller based using the LevenbergMarquardt (LM) backpropagation algorithm. The learning technique in neural networks attempts to find a set of weights that fits with a training set. As seen in Figure 3 [9], $p$ is the data vector exhibited to the network, $w$ is the weight of the network and $a$ is the equivalent output vector predicted by the network. 


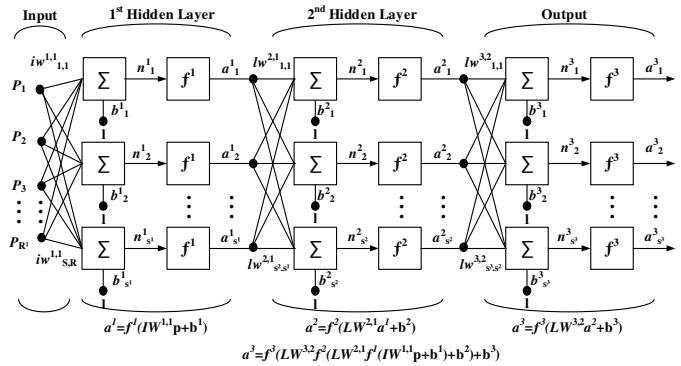

Figure 3. Input and output of ANN

For the proposed ANN network, the system uses voltage (V) and current (I) as the inputs and the PI controller gains are the target outputs. The proposed ANN network was trained using offline simulation data, for a system shown in Figure 4, correlating the inputs and the outputs for different operating conditions such as light load and with and without fault condition, heavy load condition and the fault occurring condition, wind speed changes. In doing this 1795 data points were collected with various values of of the P and I gains, $K p$ and $K i$, as well as loading conditions. Each was then classified as providing either a stable or unstable operating condition.

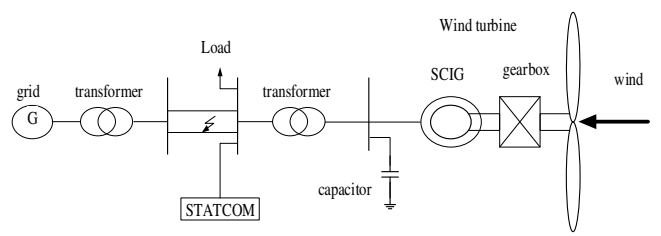

Figure 4. Single line diagram of simulation system

Subsequently, the ANN was provided with a training data set of 1257 points and 269 data points for both the validation and the testing set. Subsequently, the trained network was connected to the AC voltage regulator of the STATCOM control loop, Figure 5, allowing $K p$ and $K i$ to adapt and to support reactive power as it is needed.

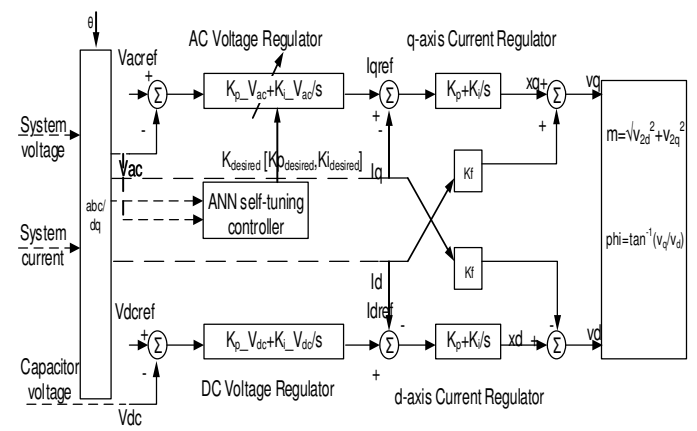

Figure 5. Block diagram of the proposed ANN selftuning STATCOM controller

\section{The Simulation}

To assess the performance of the controller a simulation utilizing two $1.5 \mathrm{MW}$ SCIG wind turbines connected in parallel with a power factor of 0.9 was implemented in MATLAB/Simulink. As the induction machine needs reactive power compensation, there is a $400 \mathrm{kVAR}$ capacitor installed near the turbine as shown in Figure 4. The grid also supplies the reactive power needed by the turbine, and active power needed to supply the load when the wind turbine is unable to meet the load alone.

The reactive power absorbed by the induction generators is partly compensated by the capacitor banks connected at the wind turbine low voltage bus. The remainder of the reactive power required to maintain the $25 \mathrm{kV}$ voltage bus close to $1 \mathrm{pu}$, is provided by the 3 MVAR STATCOM. The effect of the reactive power compensation device in the system has been analysed with the active power output, reactive power, rotor speed, voltage and current observed.

To illustrate the performance of the ANN based controller four test conditions were examined:

1. A base case where the system is operating with a $1 \mathrm{MW}$ load without faults and without compensation of reactive power from STATCOM

2. A three-phase to ground fault is introduced to the base case.

3. A three-phase to ground fault is introduced to systems compensated by a STATCOM with a fixed gain PI controller and varying load conditions.

4. A fault is introduced to a heavily loaded system compensated by a STATCOM with the proposed self-tuning PI controller STATCOM

\section{SIMULATION STUDY RESULTS}

Now in charactering, the performance of the ANN controller on the STATCOM, the effect of reactive power compensation equipment in the system was analysed. In doing this the active power output $(\mathrm{P})$, reactive power $(\mathrm{Q})$, rotor speed, voltage and current were observed.

In doing this it should be noted that the reactive power absorbed by the induction generators is partly compensated by the capacitor banks connected at wind turbine low voltage bus. The remainder of the reactive power required to maintain the $25 \mathrm{kV}$ voltage at the load bus close to 1 per unit is provided by the 3 MVAR STATCOM.

\section{Case 1: Base Case}

In the first scenario, the system under $1 \mathrm{MW}$ load operates normally, without faults and without compensation of reactive power from STATCOM as shown in Figure 6. The system operates reaches steady state after $8 \mathrm{~s}$, and the wind generator under normal and light load remains stable across the simulation time. 


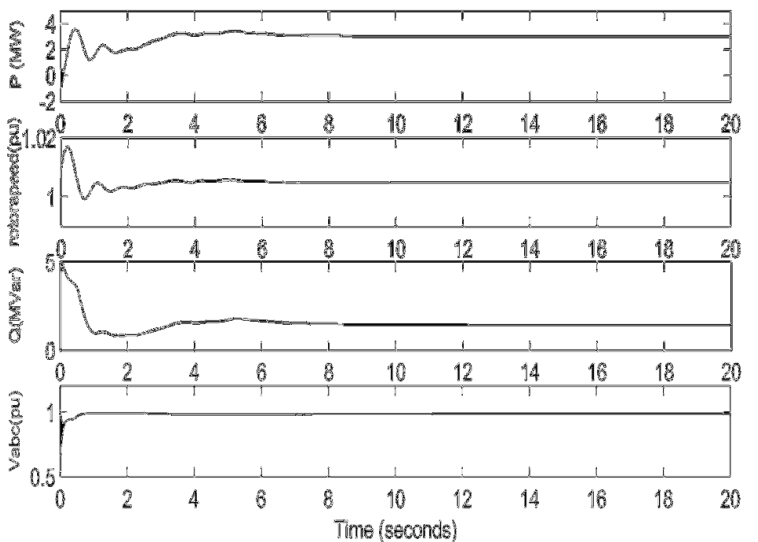

Figure 6. Load 1MW without fault and without STATCOM

Case 2: Three phase fault

In the second scenario, a three-phase to ground fault was applied in one of the double circuit lines at a time of $10 \mathrm{~s}$, after the system reaches steady state, subsequently the fault was cleared after $150 \mathrm{~ms}$. In Figure 7, it can be seen that the voltage drops during the fault period leading to an increase in the rotor speed of the turbines. Without compensation from the STATCOM, the wind generator rotor speed increases rapidly and thus leads to a complete loss of stability within the system. Such a scenario has potential serious consequences, including serious damage to the turbine.

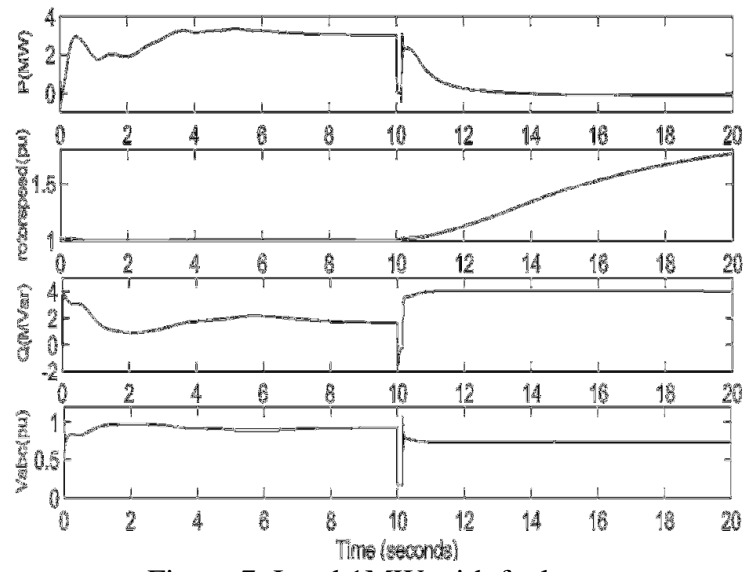

Figure 7. Load 1MW with fault

Case 3: System compensated by a STATCOM with a fixed gain PI controller.

For case 3 a STATCOM is connected near the wind turbine to provide the reactive power needed by the SCIG used by the wind turbine. The STATCOM is in voltage regulation mode to keep the voltage near to $1 \mathrm{pu}$ by providing reactive power needed. When the fault occurs, at a time of $10 \mathrm{~s}$, the wind generator rotor speed rapidly increases. However, the STATCOM is able to provide the injection of adequate reactive power needed to overcome this.
Thus, the voltage can be recovered and the system can restore its normal operation condition as shown in Figure 8.

However, as the load is increased from $1 \mathrm{MW}$ to 4 MW, it takes more time for the voltage to be restored (Figure 9), and when a heavy load is applied (8 MW), the STATCOM loses its ability to maintain the wind generator rotor speed as shown in Figure 10. The high value of the rotor speed impairs the active power output and the terminal voltage and the system loses its stability. This is due to the limitation of robustness of the fixed gain PI controller.

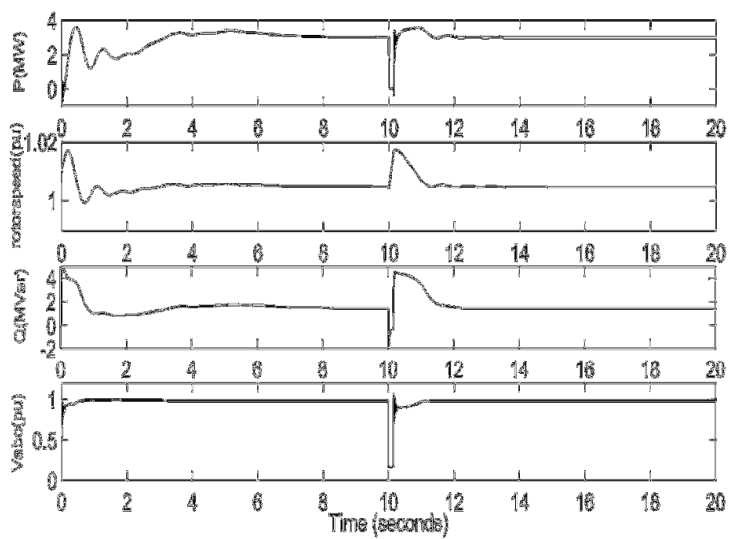

Figure 8. Load 1MW with fault and STATCOM

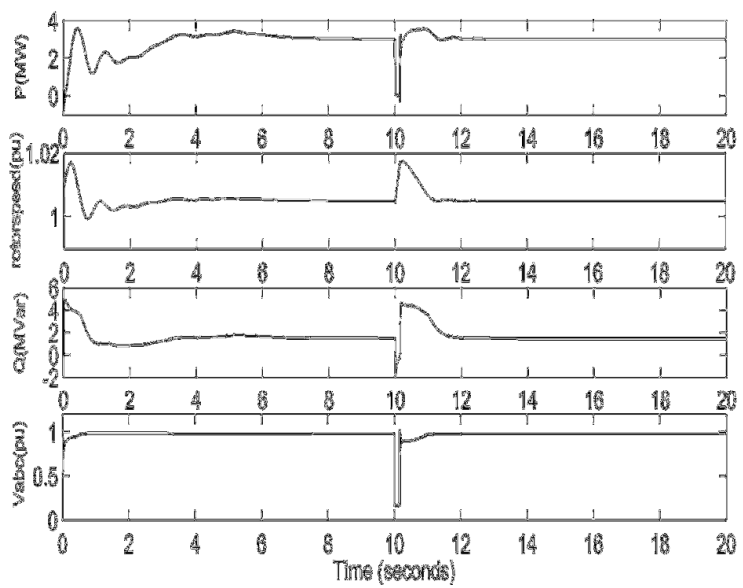

Figure 9. Load 4MW with fault and STATCOM 

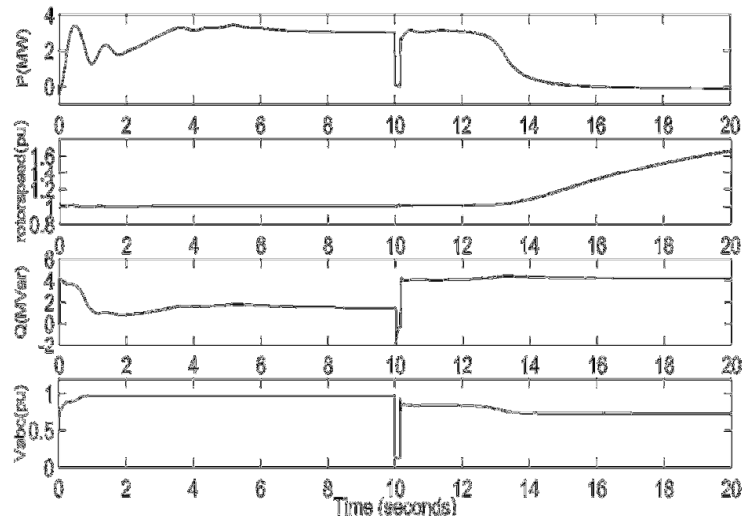

Figure 10. Load 8MW with fault and STATCOM Case 4: System compensated by a STATCOM with the proposed self-tuning PI controller STATCOM when Heavy load is applied and also the fault.

In the final case with the proposed self-tuning PI controller STATCOM connected on the AC voltage regulator, the gains can be adapted accordingly based on the system voltage and current. Therefore, the reactive power compensation can be maximised to support the reactive power needed under the heavy loading and fault conditions, hence the rotor speed can be maintained under normal condition. Hence, the active power output and the terminal voltage also achieve stability as shown in Figure 11.
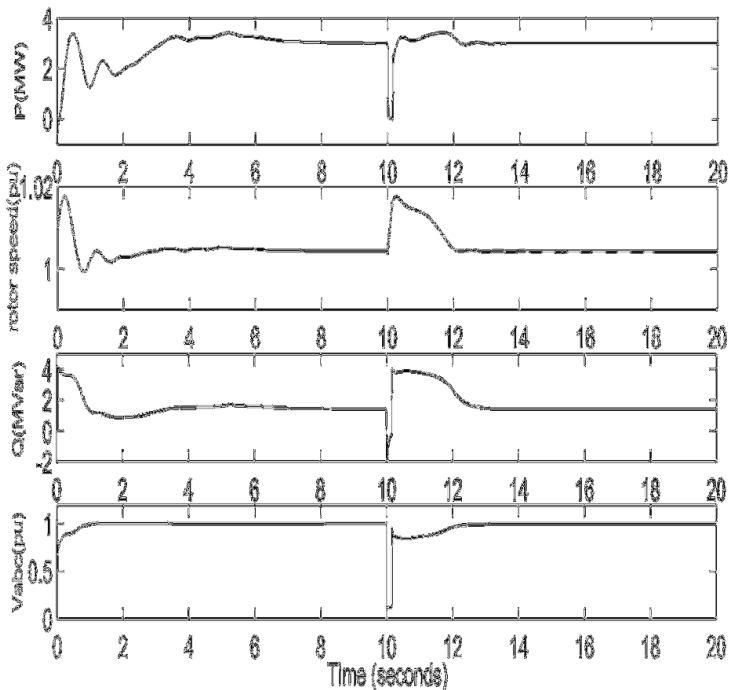

Figure 11. Load 8MW with fault, Kp Ki changes based on ANN output

\section{CONCLUSION}

Now in STATCOM $V_{a c}$ regulator as the main regulator that determines the reactive power needed from $I_{q}$. This value is regulated through the $P$ and $I$ gains to get a sufficient value that can control the reactive power whether it is generated or absorbed. In doing this the system is stable under normal operating conditions. When there is a fault, without the STATCOM, terminal voltage is not only very low but also loses its stability. With the fixed gain PI controller STATCOM, the voltage can be recovered but as the load changes significantly, the fixed PI controller STATCOM cannot maintain the system stability.

Through the series of scenarios presented, it was shown that with the proposed ANN based selftuning PI controller STATCOM can maintain such a power system's voltage stability. Moreover, the system stability is maintained with adequate reactive power injected into the system. The proposed controller is shown to be effective under different extreme conditions, such as from light to heavy loads, a short fault time and with weakened grid support.

\section{REFERENCES}

[1] J. Morren, S. W. H. d. Haan, W. L. Kling, and J. A. Ferreira, "Wind turbines emulating inertia and supporting primary frequency control," IEEE Transactions on Power Systems, vol. 21, pp. 433-434, 2006.

[2] J. M. Carrasco, L. G. Franquelo, J. T. Bialasiewicz, E. Galván, R. C. P. Guisado, M. Á. M. Prats, et al., "Power-electronic systems for the grid Integration of renewable energy sources: A survey," IEEE Transactions on Industrial Electronics, vol. 53, pp. 1002-1016, 2006.

[3] B. Singh, R. Saha, A. Chandra, and K. AlHaddad, "Static synchronous compensators (STATCOM): a review," Power Electronics, IET vol. 2, pp. 297-324, 2009.

[4] R. M. M. Pereira, C. M. M. Ferreira, and F. P. M. Barbosa, "Comparative study of STATCOM and SVC performance on dynamic voltage collapse of an electric power system with wind generation," IEEE Latin America Transactions, vol. 12, 2014.

[5] M. Sedighizadeh, A. Rezazadeh, and M. Parayandeh, "Comparison of SVC and STATCOM impacts on wind farm stability connected to power system," International Journal of Engineering and Applied Sciences (IJEAS), vol. 2, pp. 13-22, 2010.

[6] N. G. Hingorani and L. Gyugyi, Understanding FACTS: concepts and technology of flexible AC transmission systems. New York: IEEE Press, 2000.

[7] MathWorks. (2014). Static synchronous compensator.

[8] C.-H. Liu and Y.-Y. Hsu, "Design of a selftuning PI controller for a STATCOM using Particle Swarm Optimization," IEEE Transactions on Industrial Electronics, vol. 57, pp. 702-715, 2010.

[9] H. Demuth and M. Beale. (2002). Neural network toolbox user's guide. 
[10] S. Varshney, L. Srivastava, and M. Pandit, "ANN based control of statcom for improving voltage profile in power system," presented at the International Conference on Power Electronics (IICPE), New Delhi, India, 2011.

[11] M. T. Hagan and M. B. Menhaj, "Training feedforward networks with the Marquardt algorithm," IEEE Transactions on Neural Network, vol. 5, pp. 989-993, 1994.

[12] M. Soleimani-Mohseni and B. Thomas, "Neural networks for self tuning of PI- and PIDcontrollers " Chalmers University of Technology, Goteborg2005. 